\title{
PRACTICAL ADVANCED ANALYSIS FOR ECCENTRICALLY BRACED FRAMES
}

\author{
Shujun $\mathrm{Hu}^{1}$ and Zhan Wang ${ }^{2, *}$ \\ ${ }^{1}$ School of Civil Engineering and Architecture, Nanchang University, Nanchang 330031, China \\ ${ }^{2}$ State Key Laboratory of Subtropical Building Science, South China University of Technology, \\ Guangzhou 510640, China) \\ *(Corresponding author: E-mail: wangzhan@scut.edu.cn)
}

Received: 19 March 2014; Revised: 23 April 2014; Accepted: 5 May 2014

\begin{abstract}
Under severe earthquakes, flexural or shear yielding of the inelastic links in eccentrically braced frames (EBFs) was often observed. The behavior of links could not be well predicted by the traditional advanced analysis method when they experienced shear yielding and strain hardening. In this paper, the analytical model of links is obtained by using three rotational subsprings and three translational subsprings with zero-length, respectively, at each element end to simulate the flexural and shear yielding behavior with strain hardening effect. For the other elements in EBFs, a spring with zero-length is provided at each end to consider yielding on the cross-sectional level. The yield functions for the links and other elements are derived based on the section assemblage concept, and a practical advanced analysis method for EBFs is proposed. The proposed elements have the same nodal degree of freedom as conventional element by condensing the non-nodal degree of freedom that introduced in the derivation. Numerical analysis shows that the proposed method has a high efficiency and accuracy as well as easy determination of the element yielding sequence.
\end{abstract}

Keywords: Eccentrically braced frames (EBFs), Advanced analysis, Shear link, Section assemblage concept, Yield function, Strain hardening

\section{INTRODUCTION}

Eccentrically braced frames (EBFs), which combine the advantages of moment resisting frame (MRF) and concentrically braced frame (CBF), are one type of hybrid structural system with good ductility and lateral stiffness. The links in EBFs are generally designed to yield prior to frame structures, acting as the "structural fuse" member. The ductility of EBFs depends on links, which is determined by the plastic rotational capacity [1]-3]. Under severe earthquake, the main structures are generally designed to be elastic with yielding of links only so that damage on the structures can be minimized.

From previous studies, the links had three types, which were shear links, flexural links and shear-flexural links. It is also known that the behavior of links had a significance effect on the seismic behavior of EBFs and the links might experience shear or/and flexural yielding [4-5]. Detailed researches on the static and dynamic behavior of links were conducted by Ricles et al. [6], Ramadan et al. [7] and Richards et al. [8], in which the analytical model of links considering the flexural yielding, shear yielding and strain hardening were obtained. These models were regarded as the "complete element", in which a plastic hinge with zero-length was assumed at each end of link while the middle of link remained elastic without yielding. For each plastic hinge, moment hinge and shear hinge were used to simulate the rotational and horizontal deformations. Multiple subsprings with elastic-perfectly plastic model were provided at each link end to simulate the strain hardening effect. However, there were no easy methods to determine whether the design requirements and expected goals were met even though the performances of all the members were known. 
The advanced analysis methods of steel frames, which included the plastic-zone method and the plastic-hinge method, have been a subject of extensive research for decades. The plastic-hinge method has been the commonly used method because of its simplicity and efficiency, which was further modified by using the refined plastic hinge analysis model proposed by Liew et al.[9], Kim et al. [10] and Chen [11]. Chan et al. [12] also proposed a new analytical model based on section assemblage concept and section spring stiffness. However, these methods could only be used to simulate flexural yielding of elements with elastic perfectly-plastic since two plastic hinges were provided at element ends. Obviously, the shear yielding behavior and strain hardening effect of elements such as links in EBFs could no longer be well predicted by the traditional advanced analysis methods.

In this paper, the advanced analytical model of links is proposed by using three rotational subsprings and three translational subsprings elements with zero-length, respectively, at each element end to simulate the flexural and shear yielding behavior and strain hardening effect. For the conventional elements in EBFs, a spring with zero-length is provided at each end to consider gradually yielding of elements. The yield functions for all the elements are derived based on the section assemblage concept, in which strain hardening effect is only considered in links. A practical advanced analysis method for EBFs is proposed by only using one element per member. The efficiency and accuracy of the proposed method is validated and the yielding sequence of all the members is obtained. The proposed method is also used to evaluate the expected design goals for the structures.

\section{ADVANCED ANALYSIS METHOD OF CONVENTIONAL ELEMENT}

\subsection{Stability Functions Accounting for Second-order Effect}

Assuming small strains and large displacement, and considering the boundary conditions, the element moment-rotation relationship that considers the second-order effects can be written as:

$$
\left\{\begin{array}{l}
M_{1}=\frac{E I}{L}\left(S_{1} \theta_{1}+S_{2} \theta_{2}\right) \\
M_{2}=\frac{E I}{L}\left(S_{2} \theta_{1}+S_{1} \theta_{2}\right)
\end{array}\right.
$$

in which $M_{1}, M_{2}$ are the element end moments; $E, I, L=$ elastic modulus, moment of inertia, and length of element; $\theta_{1}, \theta_{2}=$ joint rotations; $S_{1}, S_{2}=$ stability function.

The simplified stability functions reported by Chen [13] are used here, and can be written as:

$$
S_{1}=\left\{\begin{array}{cl}
\frac{\alpha \sin \alpha-\eta \alpha^{2} \cos \alpha}{2-2 \cos \alpha-\eta \alpha \sin \alpha} ; & P<0 \\
\frac{4+\beta}{1+\beta} ; & P=0 \\
\frac{\eta \alpha^{2} \cosh \alpha-\alpha \sinh \alpha}{2-2 \cosh \alpha+\eta \alpha \sinh \alpha} ; & P>0
\end{array} \quad S_{2}=\left\{\begin{array}{cc}
\frac{\eta \alpha^{2}-\alpha \sin \alpha}{2-2 \cos \alpha-\eta \alpha \sin \alpha} ; & P<0 \\
\frac{2-\beta}{1+\beta} & P=0 \\
\frac{\alpha \sinh \alpha-\eta \alpha^{2}}{2-2 \cosh \alpha+\eta \alpha \sinh \alpha} ; & P>0
\end{array}\right.\right.
$$


in which $\eta=1+\mu P / G A, \quad \beta=12 \mu E I / G A l^{2}, \alpha=l \sqrt{|P| /(\eta E I)} \cdot \mu=$ section coefficient for shear deformation; $P=$ axial force (positive in tension and negative in compression); $G=$ shear modulus.

\subsection{Initial and Full Yield Functions}

Section assemblage concept [14] is derived on the basis of plate assemblage of a $\mathrm{H}$ or I section. It is assumed that web takes axial loads and the remaining unyielded part resists moments. For analysis of I or $\mathrm{H}$ sections, the section is idealized as composed of several rectangular strips. Section parameters such as breadth, depth, flange and web thickness are used to calculate section capacity.

Initial yield function. Section stiffness will reduce gradually after the axial load and moment exceed first yield value. In the presence of residual stress and axial force, initial yield function can be written as

$M_{e r}=\left(f_{y}-f_{r}-P / A\right) W_{e y}$

in which $M_{e r}=$ first yield moment, $W_{e y}=$ elastic modulus, $f_{r}=$ maximum residual stress.

Residual stress is based on the recommendation by ECCS [15], and the maximum residual stress is assumed to be dependent on the ratio of depth/breadth. The distribution is shown in Figure 1.

Full yield function. Section stiffness will be reduced to zero after the axial loads and moments exceed full yield value, and residual stress is ignored.

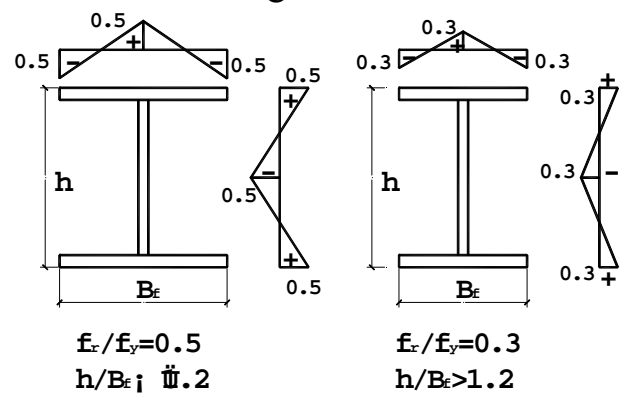

Figure 1. ECCS Residual Stress Distribution for I-section

The half depth of plastic zone for axial load can be written as:

$$
\begin{cases}\lambda=\frac{P}{2 f_{y} t_{w}} & \text { for } \lambda \leq \frac{h_{w}}{2} \\ \lambda=\frac{P-f_{y} t_{w} h_{w}}{2 f_{y} B_{f}}+\frac{h_{w}}{2} & \text { for } \frac{h_{w}}{2} \leq \lambda \leq \frac{h_{w}}{2}+h_{f}\end{cases}
$$

Upon determination of plastic zone in the section, moment resisted by the remaining unyielded zones can be written as

$$
\begin{cases}M_{p c}=\left[W_{p y}-\lambda^{2} t_{w}\right] f_{y} & \text { for } \lambda \leq \frac{h_{w}}{2} \\ M_{p c}=\left[\frac{h^{2}}{4}-\lambda^{2}\right] B_{f} f_{y} & \text { for } \quad \frac{h_{w}}{2} \leq \lambda \leq \frac{h_{w}}{2}+h_{f}\end{cases}
$$

in which $M_{p c}=$ the reduced plastic moment in the presence of axial force, $W_{p y}=$ plastic modulus, $f_{y}=$ yield stress, $h_{w}, t_{w}=$ web depth and thickness, $B_{f}, h_{f}=$ flange breadth and thickness, $h=$ section depth. 
The curves of first and full yield surface are determined by Eq.3 and Eq.5, as shown in Figure 2. From Eq. 3 and Eq. 5, the $M_{e r}$ and $M_{p c}$ are controlled by axial loads and residual stress, and section spring stiffness $S_{c}[14]$ can be written as

$$
\begin{cases}S_{c}=\infty & \text { for } M<M_{e r} \\ S_{c}=\frac{6 E I}{L} \frac{\left|M_{p c}-M\right|}{\left|M-M_{e r}\right|} & \text { for } M_{e r} \leq M<M_{p c} \\ S_{c}=0 & \text { for } M \geq M_{p c}\end{cases}
$$

So from Eq. 6, the magnitude of $S_{c}$ is determined by first yield moment and full yield moment.

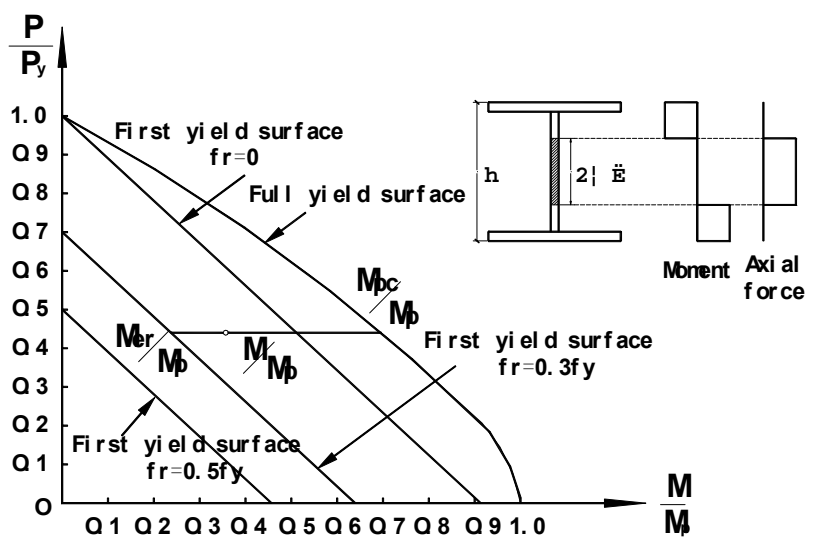

Figure 2. First Yield and Full Yield Surfaces of Section

\subsection{Element Stiffness Formulation Accounting for Plasticity Effect}

Advanced analysis of steel frames assumes plastic hinges occur only at both ends, and a spring with zero-length at each end is assumed to account for the section yielding. The deformed element with end-section pseudo-spring is shown in Figure 3. Owing to the gradual yielding of the end springs, the rotational stiffness and displacement on the both sides of each spring are generally unequal.

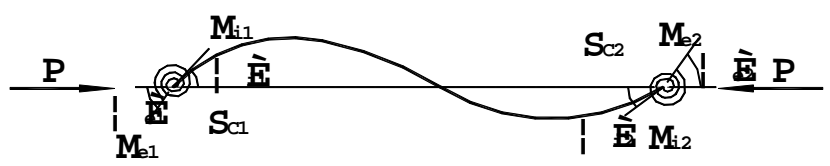

Figure 3. Internal Forces of an Element with End-section Pseudo-spring

Considering the moment equilibrium condition at each spring, the incremental equation can be written as

$$
\left\{\begin{array}{l}
\Delta M_{e} \\
\Delta M_{i}
\end{array}\right\}=\left[\begin{array}{cc}
S_{c} & -S_{c} \\
-S_{c} & S_{c}
\end{array}\right]\left\{\begin{array}{l}
\Delta \theta_{e} \\
\Delta \theta_{i}
\end{array}\right\}
$$

in which $\Delta M_{e}, \Delta \theta_{e}=$ the incremental moment and rotation between the global node and the spring; $\Delta M_{i}, \Delta \theta_{i}=$ the incremental moment and rotation between the spring and the beam at each end.

Combining the section spring stiffness and stability function, the element incremental moment-rotation relationship can be written as 
$\left\{\begin{array}{l}\Delta M_{e 1} \\ \Delta M_{i 1} \\ \Delta M_{i 2} \\ \Delta M_{e 2}\end{array}\right\}=\left[\begin{array}{cccc}S_{c 1} & -S_{c 1} & 0 & 0 \\ -S_{c 1} & S_{c 1}+K_{11} & K_{12} & 0 \\ 0 & K_{21} & S_{c 2}+K_{22} & -S_{c 2} \\ 0 & 0 & -S_{c 2} & S_{c 2}\end{array}\right]\left\{\begin{array}{c}\Delta \theta_{e 1} \\ \Delta \theta_{i 1} \\ \Delta \theta_{i 2} \\ \Delta \theta_{e 2}\end{array}\right\}$

in which $K_{11}=K_{22}=S_{1} E I / L, K_{12}=K_{21}=S_{2} E I / L, S_{1}, S_{2}$ as shown in Eq. 2.

Eliminate non-nodal degrees of freedom. With $\Delta \theta_{i 1}$ and $\Delta \theta_{i 2}$ condensed, Eq. 8 becomes

$\left(K_{e e}-K_{e i} K_{i i}^{-1} K_{e i}^{T}\right)\left\{\Delta \theta_{e e}\right\}=\left\{\Delta M_{e e}\right\}-K_{e i} K_{i i}^{-1}\left\{\Delta M_{i i}\right\}$

in which $\left\{\Delta M_{e e}\right\}$ and $\left\{\Delta M_{i i}\right\}$ are the incremental nodal moments vectors at both ends; $\left\{\Delta \theta_{e e}\right\}$ and $\left\{\Delta \theta_{i i}\right\}$ are the incremental nodal rotation vectors corresponding to these moments.

$$
\begin{aligned}
& \left\{\Delta M_{e e}\right\}=\left[\Delta M_{e 1}, \Delta M_{e 2}\right]^{T},\left\{\Delta M_{i i}\right\}=\left[\Delta M_{i 1}, \Delta M_{i 2}\right]^{T} \\
& \left\{\Delta \theta_{e e}\right\}=\left[\Delta \theta_{e 1}, \Delta \theta_{e 2}\right]^{T},\left\{\Delta \theta_{i i}\right\}=\left[\Delta \theta_{i 1}, \Delta \theta_{i 2}\right]^{T} \\
& K_{e e}=\left[\begin{array}{cc}
S_{c 1} & 0 \\
0 & S_{c 2}
\end{array}\right], K_{e i}=\left[\begin{array}{cc}
-S_{c 1} & 0 \\
0 & -S_{c 2}
\end{array}\right] \\
& K_{i i}=\left[\begin{array}{cc}
S_{c 1}+K_{11} & K_{12} \\
K_{21} & S_{c 2}+K_{22}
\end{array}\right]
\end{aligned}
$$

Whilst loads are only applied at the nodes, the internal incremental moments $\left\{\Delta M_{i i}\right\}=\{0\}$, and Eq.9 can be written as

$$
\left\{\Delta M_{e e}\right\}=\left(K_{e e}-K_{e i} K_{i i}^{-1} K_{e i}^{T}\right)\left\{\Delta \theta_{e e}\right\}
$$

From Eq. 8 to 11, the incremental stiffness relationship accounting for section yielding becomes

$$
\left\{\begin{array}{l}
\Delta P_{1} \\
\Delta M_{e 1} \\
\Delta M_{e 2}
\end{array}\right\}=\left[\begin{array}{ccc}
E A / L & 0 & 0 \\
0 & S_{c 1}-S_{c 1}^{2}\left(S_{c 2}+K_{22}\right) / \beta & S_{c 1} S_{c 2} K_{12} / \beta \\
0 & S_{c 1} S_{c 2} K_{21} / \beta & S_{c 2}-S_{c 2}^{2}\left(S_{c 1}+K_{11}\right) / \beta
\end{array}\right]\left\{\begin{array}{l}
\Delta u \\
\Delta \theta_{e 1} \\
\Delta \theta_{e 2}
\end{array}\right\}
$$

in which $\Delta P_{1}$ is the increment axial force, $\beta=\left(S_{\mathrm{c} 1}+K_{11}\right)\left(S_{\mathrm{c} 2}+K_{22}\right)-K_{12} K_{21}$.

\section{IMPROVED ADVANCED ANALYSIS ACCOUNTING FOR LINKS}

Under severe earthquake, the links are designed to yield firstly by the high moments or shears. The analytical model of links considering the static and dynamic behavior have been proposed by many researches [6] [8]. The accuracy of link analytical model is of crucial importance to the overall performance of EBFs. 


\subsection{Link Element Model and Yield Surfaces}

The advanced analytical model of links that can be accurately modeled is attempted in this paper, as shown in Figure 4. The following three assumptions are made: (1) The out-of-plane degrees of freedom is neglected; (2) As link is yielding and subsequent strain hardening, there is no interaction between the shear and moment; (3) There is also no interaction between the shear and axial force $[16]$.

A plastic hinge includes shear hinge and moment hinge with zero-length is assumed at each end of link, and the inner element between two plastic hinges should be constrained to remain elastically under any condition, so the deformation is only confined to occur at the ends. The load-displacement relationship of link is multilinear hardening modeling accounting for strain hardening effect. As the interaction between shear and moment is neglected, the shear hinge and moment hinge are independent. Each shear hinge and moment hinge have been divided into three translational subsprings and rotational subsprings, and each subspring has specific deformation mode and load-displacement relationship, as shown in Figure 4.

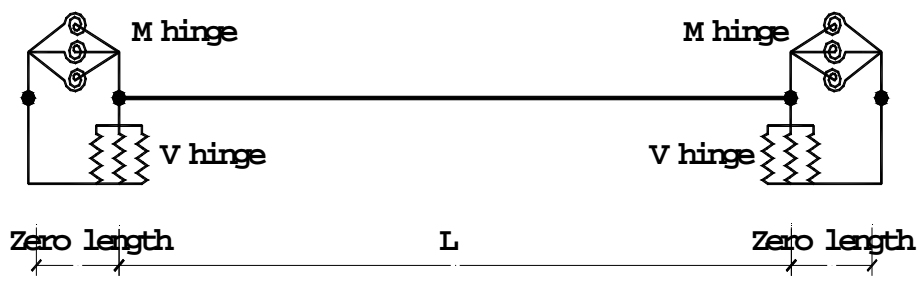

Figure 4. Link Model

Yield surfaces of links. The effect of residual stress in initial yield function, in which considers the interaction between axial forces and moment for flexural links, cannot be ignored. The effect of strain hardening is also significant to the yield surface. Section stiffness will be gradually reduced to zero when the shear and moment increase and exceed the full yield surface 3 . The yield surfaces for all kinds of links can be shown in Figure 5.

\subsection{Link Strain Hardening}

In the EBFs, shear yielding, flexural yielding and shear-flexural yielding may be experienced depending on different kinds of links. The load-displacement curves are multilinear hardening modeling with the behavior of links for reasonable design. When the shear or moment exceeds $V_{3}$ or $M_{3}$, as shown in Figure 6, the shear hinge or moment hinge is formed. 


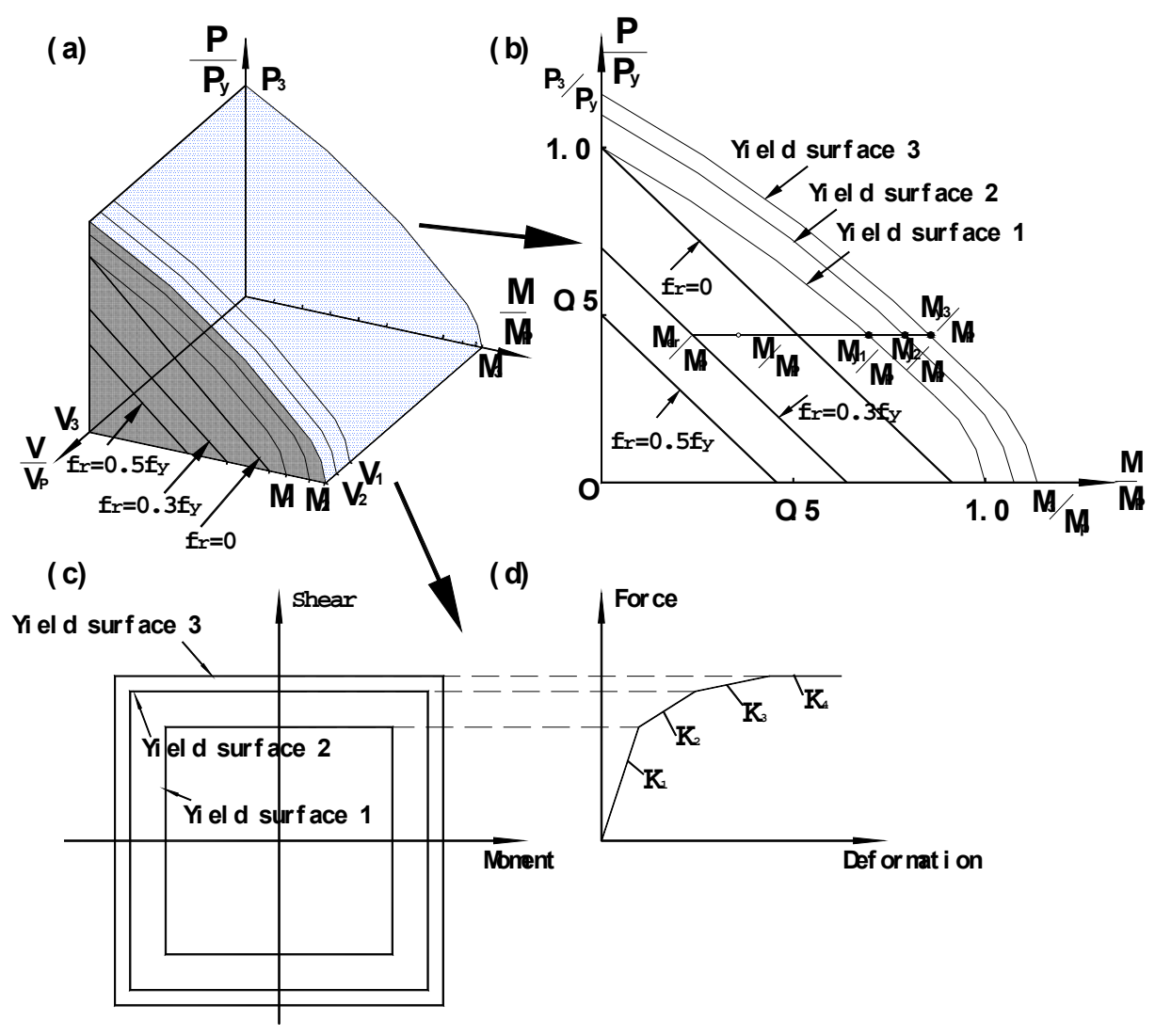

(a) Yield surface of links; (b) Yield surface of flexural links

(c) Uncoupled yield surface for shear and moment; (d) Load-displacement curve for link model

Figure 5. Yield Surfaces of Links

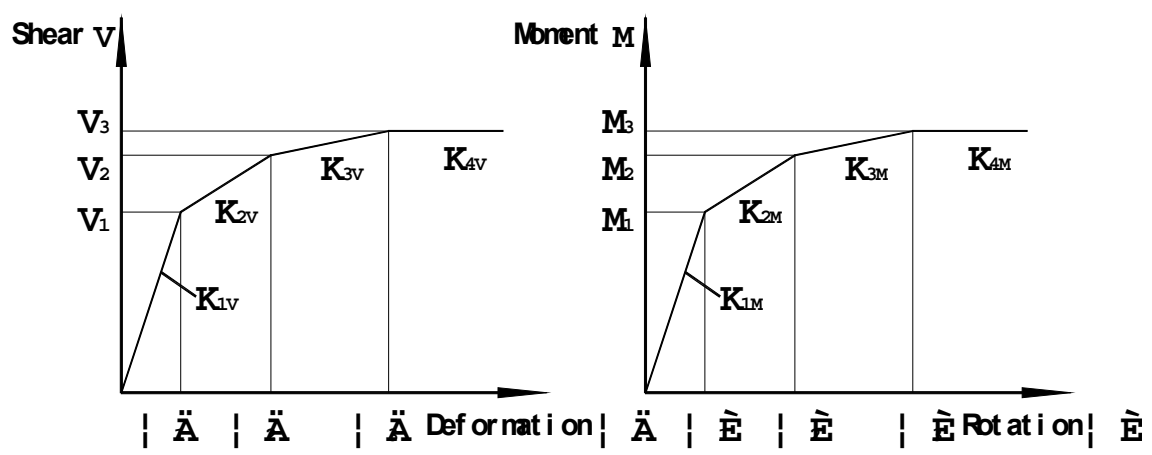

Figure 6. Shear Force and Moment for Multilinear Link Model

In Figure 6 , the $K$ values reported by Ricles and Popov [8] are used here, and can be written as:

$$
\begin{cases}K_{2 V}=0.03 K_{1 V} ; & K_{2 M}=0.03 K_{1 M} \\ K_{3 V}=0.015 K_{1 V} ; & K_{3 M}=0.015 K_{1 M} \\ K_{4 V}=0 ; & K_{4 M}=0\end{cases}
$$


in which $K_{1 V}=G A_{\text {web }} / e$; $K_{1 M}=6 E I / e ; E, I, e=$ elastic modulus, moment of inertia, and length of link; $A_{w e b}=$ area of the web of link.

$M_{y}=M_{p} ; \quad V_{y}=0.9 V_{p}$

The plastic moment capacity $M_{p}$ and plastic shear capacity $V_{p}$ can be expressed as:

$M_{p}=Z \sigma_{y} ; \quad V_{p}=\tau_{y}\left(d-t_{f}\right) t_{w} ; \tau_{y}=\sigma_{y} / \sqrt{3}$

in which $\mathrm{Z}=$ section plastic modulus of link; $d=$ section depth of link; $t$, $t_{w}=$ section flange and web thickness of link; $\sigma_{y}, \tau_{y}=$ yield stress in tension and shear.

The $V$ values and $M$ values, as shown in Figure 6, are obtained in many test for links. All the values reported by Ricles and Popov [8] are also used here, and can be expressed in Table 1.

Table 1. Yielding Values of the Shear Forces and Moments for the Multilinear Inelastic Link Element

\begin{tabular}{|c|c|c|c|c|c|c|}
\hline & \multicolumn{2}{|c|}{ First yielding } & \multicolumn{2}{c|}{ Second yielding } & \multicolumn{2}{c|}{ Third yielding } \\
\cline { 2 - 7 } & $\begin{array}{c}\text { Shear } \\
V_{1}\end{array}$ & $\begin{array}{c}\text { Moment } \\
M_{1}\end{array}$ & $\begin{array}{c}\text { Shear } \\
V_{2}\end{array}$ & $\begin{array}{c}\text { Moment } \\
M_{2}\end{array}$ & $\begin{array}{c}\text { Shear } \\
V_{3}\end{array}$ & $\begin{array}{c}\text { Moment } \\
M_{3}\end{array}$ \\
\hline $\begin{array}{c}\text { Ricles and } \\
\text { Popov (1994) }\end{array}$ & $1.0 V_{p}$ & $1.0 M_{p}$ & $1.26 V_{p}$ & $1.13 M_{p}$ & $1.40 V_{p}$ & $1.20 M_{p}$ \\
\hline
\end{tabular}

The link multilinear hardening modeling at each end is divided into three zero-length translational subsprings and three zero-length rotational subsprings, and each subspring has an elastic perfectly-plastic load-displacement relationship, as shown in Figure 7. The force and stiffness of each subspring can be obtained in Table 1 and Eq.13, so the behavior of links in EBFs can be well predicted.

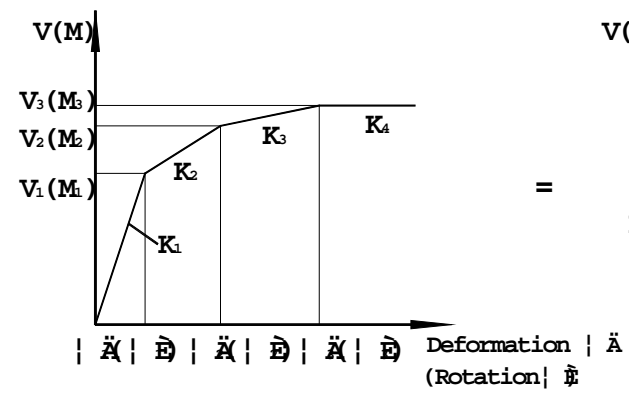

$\mathbf{V}(\mathrm{M})$
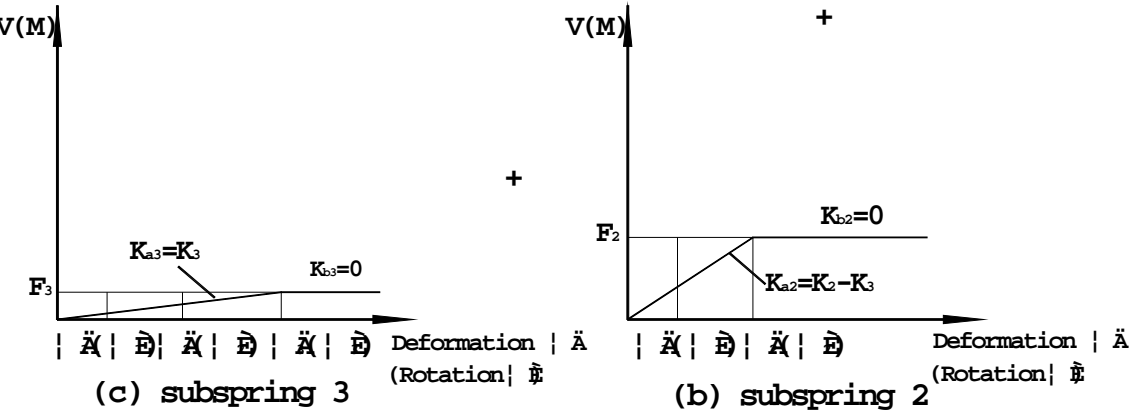

Figure 7. Load-displacement Relationship of Subsprings 


\subsection{Advanced Analytical Model of Flexural Links}

The element stiffness accounting for strain hardening will be influenced by changing in moment at each end of flexural link. Based on section assemblage concept and section spring stiffness, the yield function and stiffness of flexural links are proposed by considering the interaction between axial force and moment.

Initial yield function. The initial yield function is the same as conventional element, as shown in Eq.3.

Other yield functions. After the strain hardening of flexural links is considered, the half depth of plastic zone for axial load becomes

$$
\begin{cases}\lambda=\frac{P}{2 \beta_{i} f_{y} t_{w}} & \text { for } \lambda \leq \frac{h_{w}}{2} \\ \lambda=\frac{P-\beta_{i} f_{y} t_{w} h_{w}}{2 \beta_{i} f_{y} B_{f}}+\frac{h_{w}}{2} & \text { for } \frac{h_{w}}{2} \leq \lambda \leq \frac{h_{w}}{2}+h_{f}\end{cases}
$$

Upon determination of plastic zone in the section, yielding moment $M_{p y}$ that resisted by the remaining unyielded zones can be written as:

$$
\left\{\begin{array}{l}
M_{p y}=\left[W_{p y}-\lambda^{2} t_{w}\right] \beta_{i} f_{y} \quad \text { for } \lambda \leq \frac{h_{w}}{2} \\
M_{p y}=\left[\frac{h^{2}}{4}-\lambda^{2}\right] B_{f} \beta_{i} f_{y} \quad \text { for } \quad \frac{h_{w}}{2} \leq \lambda \leq \frac{h_{w}}{2}+h_{f}
\end{array}\right.
$$

in which $\beta_{i}=$ material enhancement factor for moment strain hardening, corresponding to the first, second and third yielding values, as shown in Figure 7. As the $\beta_{i}$ equals $\beta_{1}, \beta_{2}$ or $\beta_{3}$, the $M_{p y}$ corresponds to $M_{y 1}, M_{y 2}$ or $M_{y 3}$, and $\beta_{1}=1, \beta_{2}=M_{2} / M_{1}, \beta_{3}=M_{3} / M_{1}$.

Based on the yielding values accounting for moment strain hardening, section spring stiffness $S_{c}$ can be written as

$$
\begin{cases}S_{c}=\infty & \text { for } M<M_{e r} \\ S_{c}=S_{p}=\frac{6 E I}{L} \frac{\left|M_{y 1}-M\right|}{\left|M-M_{e r}\right|} & \text { for } M_{e r} \leq M<M_{y 1} \\ S_{c}=0 & \text { for } M \geq M_{y 1}\end{cases}
$$

Assuming the right of link is elastic under any condition, and moment at left is changed, the section subspring stiffness and subelement stiffness in extreme conditions can be written as

(a) subspring is full elastic

The section subspring stiffness $S_{c a}=\infty$, subelement stiffness $K_{M a}$ can be written as:

$$
K_{M a}=\left[\begin{array}{ccc}
E A / L & 0 & 0 \\
0 & K_{11} & K_{12} \\
0 & K_{21} & K_{22}
\end{array}\right]
$$


(b) subspring is partially yielded

The section subspring stiffness $S_{c a}=S_{p}$, subelement stiffness $K_{M b}$ can be written as:

$$
K_{M b}=\left[\begin{array}{ccc}
E A / L & 0 & 0 \\
0 & K_{11} /\left(1+K_{11} / S_{c 1}\right) & K_{12} /\left(1+K_{11} / S_{c 1}\right) \\
0 & K_{12} /\left(1+K_{11} / S_{c 1}\right) & K_{22}-K_{12} K_{21} /\left(K_{11}+S_{c 1}\right)
\end{array}\right]
$$

(c) subspring is fully yielded

The section subspring stiffness $S_{c a}=0$, subelement stiffness $K_{M c}$ can be written as:

$$
K_{M c}=\left[\begin{array}{ccc}
E A / L & 0 & 0 \\
0 & 0 & 0 \\
0 & 0 & K_{22}-K_{12} K_{21} / K_{11}
\end{array}\right]
$$

in which $K_{11}=K_{22}=S_{1} E I / L, K_{12}=K_{21}=S_{2} E I / L . S_{1}, S_{2}=$ stability function accounting for shear deformation.

When the link moment exceeds first yielding moment $M_{y 1}$, only full elastic or full yield can occur in all the subsprings. As changes in moment at left end of flexural links, section spring stiffness of each subspring may be equal to $S_{c a 1}, S_{c a 2}$ or $S_{c a 3}$. The element stiffness is equal to the sum of subelements stiffness. Several conditions of element stiffness $K$ can be expressed in Table 2:

Table 2. Section Subspring Stiffness and Element Stiffness $K$ for Flexural Links

\begin{tabular}{|c|c|c|c|c|c|}
\hline & $M<M_{e r}$ & $M_{e r} \leq M<M_{y 1}$ & $M_{y 1} \leq M<M_{y 2}$ & $M_{y 2} \leq M<M_{y 3}$ & $M>M_{y 3}$ \\
\hline$S_{c a 1}$ & $\infty$ & $S_{p}$ & 0 & 0 & 0 \\
\hline$S_{c a 2}$ & $\infty$ & $\infty$ & $\infty$ & 0 & 0 \\
\hline$S_{c a 3}$ & $\infty$ & $\infty$ & $\infty$ & $\infty$ & 0 \\
\hline$K$ & $K_{M a}$ & $\begin{array}{c}\beta_{1 M} K_{M b}+ \\
\left(\beta_{2 M}+\beta_{3 M}\right) K_{M a}\end{array}$ & $\begin{array}{c}\beta_{1 M} K_{M c}+ \\
\left(\beta_{2 M}+\beta_{3 M}\right) K_{M a}\end{array}$ & $\begin{array}{c}\left(\beta_{1 M}+\beta_{2 M}\right) K_{M c} \\
+\beta_{3 M} K_{M a}\end{array}$ & $K_{M c}$ \\
\hline
\end{tabular}

in which $\beta_{1 M}=\left(K_{1 M}-K_{2 M}\right) / K_{1 M} ; \beta_{2 M}=\left(K_{2 M}-K_{3 M}\right) / K_{1 M} ; \beta_{3 M}=K_{3 M} / K_{1 M} . K_{1 M}, K_{2 M}$ and $K_{3 M}$ are as shown in Eq.13. When $M>M_{y 3}$, all the subsprings at the left of link are in plastic stage.

If the moment at the right of link is changed as the left, the element stiffness $K$ can be formed by only changing the $K_{M a}, K_{M b}$ and $K_{M c}$ in Table 2.

\subsection{Advanced Analytical Model of Shear Links}

When the link is designed as shear link in EBFs, shear failure will precede flexural failure. The conventional advanced analytical model cannot predict the behavior of shear yielding.

As the interaction between the shear and axial force is neglected, the stability function $S_{1}$ and $S_{2}$ that consider the shear deformation and ignore the effect of axial force can be written as

$$
S_{1}=\frac{4+\beta}{1+\beta}, \quad S_{2}=\frac{2-\beta}{1+\beta}
$$

in which $\beta=12 \mu E I /\left(G A l^{2}\right)$. 
Considering the effect of shear strain hardening, element stiffness of shear links will reduce gradually with the shear increasing. Assume $\alpha=G A / l$, then $\alpha_{1}=\lambda \alpha=\lambda G A / l$, in which $\lambda=$ material enhancement factor for shear strain hardening. So $\beta$ becomes

$\beta=\frac{12 \mu E I}{\lambda G A l^{2}}=\frac{12 \mu E I}{\lambda \alpha l^{3}}$

in which $r=12 \mu E I /\left(\alpha l^{3}\right)$. Combined with the Eq. 22 and Eq.23, $S_{1}$ and $S_{2}$ can become

$$
\left\{\begin{array}{l}
S_{1}=\frac{4 \lambda+r}{\lambda+r}=\frac{3 \lambda}{\lambda+r}+1 \\
S_{2}=\frac{2 \lambda-r}{\lambda+r}=\frac{3 \lambda}{\lambda+r}-1
\end{array}\right.
$$

The element stiffness $K$ accounting for shear strain hardening can be written as:

$$
K_{V}=\frac{E I}{L} \frac{3 \lambda}{\lambda+r}\left[\begin{array}{lll}
0 & 0 & 0 \\
0 & 1 & 1 \\
0 & 1 & 1
\end{array}\right]+\frac{E I}{L}\left[\begin{array}{ccc}
A / I & 0 & 0 \\
0 & 1 & -1 \\
0 & -1 & 1
\end{array}\right]
$$

From Eq. 25, different $\lambda$ corresponds to different element stiffness $K$. When $\lambda=1$, the $K$ is identical to the elastic stiffness that considers the shear deformation effect; when $\lambda=0$, the incremental shear equals zero, and the $K$ is only related to moment.

Whilst loads are only applied at the nodes in EBFs, the shear $V$ is constant along the link. According to the shear yielding values in Table 1, several conditions of element material enhancement factor $\lambda$ can be expressed in Table 3 .

Table 3. Shear Yielding Values and Element Material Enhancement Factor $\lambda$ for Shear Links

\begin{tabular}{|c|c|c|c|c|}
\hline & $V<V_{1}$ & $V_{1} \leq V<V_{2}$ & $V_{2} \leq V<V_{3}$ & $V>V_{3}$ \\
\hline$\lambda_{1}$ & $\beta_{1 V}$ & 0 & 0 & 0 \\
\hline$\lambda_{2}$ & $\beta_{2 V}$ & $\beta_{2 V}$ & 0 & 0 \\
\hline$\lambda_{3}$ & $\beta_{3 V}$ & $\beta_{3 V}$ & $\beta_{3 V}$ & 0 \\
\hline$\lambda$ & 1 & $\lambda_{2}+\lambda_{3}$ & $\lambda_{3}$ & 0 \\
\hline
\end{tabular}

in which $\beta_{1 V}=\left(K_{1 V}-K_{2 V}\right) / K_{1 V}, \beta_{2 V}=\left(K_{2 V}-K_{3 V}\right) / K_{1 V}, \beta_{3 V}=K_{3 V} / K_{1 V}$. The $K_{1 V}, K_{2 V}$ and $K_{3 V}$ are as shown in Eq.13. The zero in Table 3 represents the subspring has yielded. When $V>V_{3}$, all the subsprings are in plastic stage. The element stiffness of shear links $K$ can be formed by only changing the $\lambda$ in Eq. 25 .

\section{NUMERICAL EXAMPLES}

\subsection{EBF with Flexural Link}

An experimental study of EBF K2 with flexural link has been reported by Shi et al.[17], it is used for the case study in this paper. The load-displacement curve of K2 is obtained by the experimental results. All the beams are H120x70x6x6, columns are H150x120x6x8, and braces are $\square 60 \times 6$. The loads and dimensions are shown in Figure $8 . E=210 \mathrm{kN} / \mathrm{mm}^{2}, f_{y}=306 \mathrm{~N} / \mathrm{mm}^{2}$ for all the members. 
In the advanced analysis of the EBF, flexural yielding, strain hardening, geometric and material nonlinearity, shear deformation and residual stress are explicated. Two kinds of analysis are carried out: (1) NC-EBF: the effect of strain hardening is ignored in EBF; (2) C-EBF: the effect of strain hardening is considered in EBF. The ultimate loads and displacements of all the analyses are compared in Table 4. In the elastic stage, the experimental value is somewhat larger than the results of analysis (1) and (2), it may be influenced by the panel zone. In the elastic-plastic stage, the ultimate load and displacement of analysis (2) are in close agreement with experimental value, but the results obtained from analysis (1) are different from others. The first plastic hinge of analysis (2) is formed at column base, and subsequent plastic hinge is formed at beam segment outside of the link, it is the same as the experimental result for the element yielding sequence. However, the first plastic hinge of analysis (1) is formed at both ends of link, and subsequent plastic hinge is at the column base. So it is important to consider the effect of moment strain hardening. The proposed practical advanced analysis method is suitable for the analysis of EBFs with flexural link, and has a high accuracy. The load-displacement curves obtained by the analyses are shown in Figure 9.

Table 4. Comparison of Ultimate Load and Displacement

\begin{tabular}{|c|c|c|}
\hline & Ultimate Load $(\mathrm{kN})$ & $\begin{array}{c}\text { Ultimate } \\
\text { displacement }(\mathrm{mm})\end{array}$ \\
\hline Experimental & 220 & 11.0 \\
\hline C-EBF & 215 & 12.4 \\
\hline NC-EBF & 201 & 9.0 \\
\hline
\end{tabular}

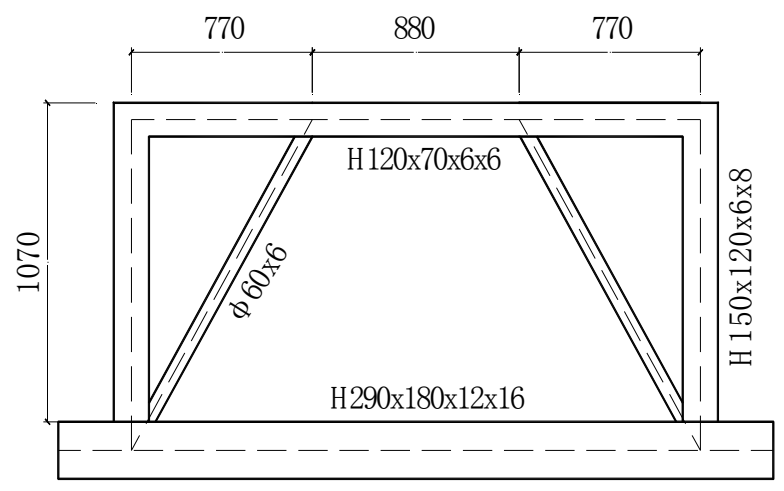

Figure 8. Eccentrically Braced Frame K2: Flexural-link

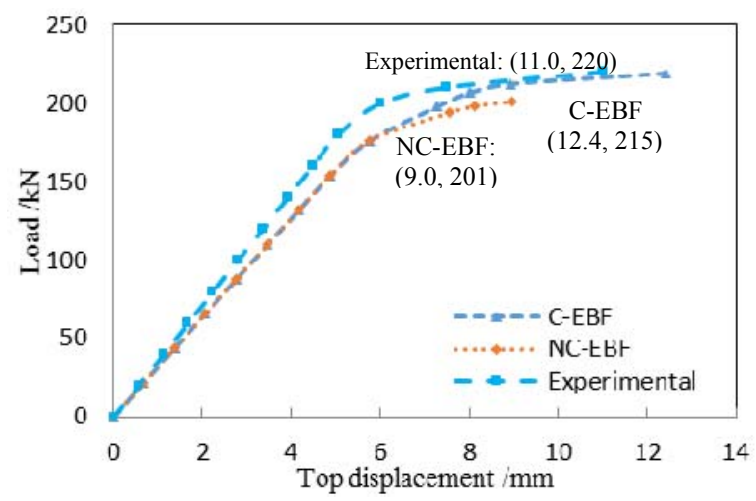

Figure 9. Load-displacement Curve of K2 


\subsection{EBF with Shear Link}

A one-storey EBF with shear link, based on the provision of Code for Seismic Design of Buildings [18], has been designed for the case study in this paper. All the beams are $H 300 \times 150 \times 6.5 \times 9$, columns are $\mathrm{H} 350 \times 350 \times 10 \times 16$, and braces are $\square 150 \times 8$. The dimensions and loads are shown in Figure $10 . E=206 \mathrm{kN} / \mathrm{mm}^{2}, f_{y}=235 \mathrm{~N} / \mathrm{mm}^{2}$ for all the members.

In the advanced analysis of this EBF, shear yielding, strain hardening, geometric and material nonlinearity, shear deformation and residual stress are explicated. Three kinds of analyses are also carried out: (1) NC-EBF: the effect of shear yielding and strain hardening is ignored in EBF; (2) C-EBF: the effect of shear yielding and strain hardening is considered in EBF; (3) Finite Element Analysis: ANSYS is used to analyze in EBF. The ultimate loads and displacements of all the analyses are compared in Figure 11. In the elastic stage, the result of analysis (3) is different from analyses (1) and (2), it may also be influenced by the panel zone. In the elastic-plastic stage, the ultimate load and displacement obtained from analysis (3) are in close agreement with analysis (2), but it is much different from analysis (1). As to the element yielding sequence, first of the analysis (2) occurs at link with shear yielding, and subsequent plastic hinge is formed at the column base. It is the same as the analysis (3), and the stress contour is shown in Figure 12. However, the yielding sequence of analysis (1) is at both ends of link with moment yielding, and subsequent is at the column base. So the effect of shear links and strain hardening are of crucial importance in EBFs. The proposed practical advanced analysis method is also suitable for the analysis of EBFs with shear link, and has a high accuracy. The load-displacement curves obtained by the analyses are shown in Figure 11.

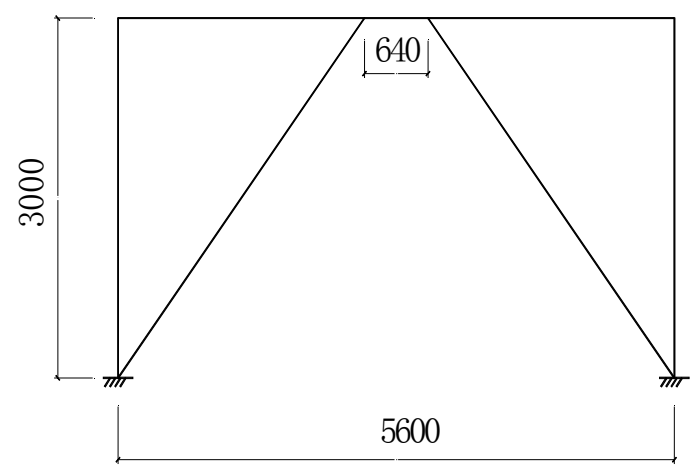

Figure 10. EBF with Shear Link

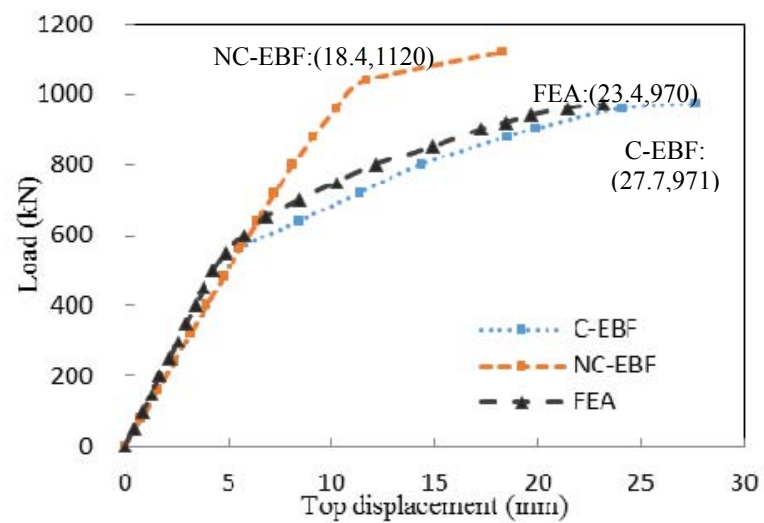

Figure 11. Load-displacement Curve of EBF with Shear Link

\subsection{Three-storey EBFs with Shear Links}

A global seismic response of two EBFs with shear links is investigated in this paper, as show in Figure 13. It is reported by Rozon et al.[19]. The sizes of beams, columns and braces in every storey are different because of the different seismic intensity, as shown in Table 5. As the seismic intensity of structure A is lower than structure B, all the section dimensions of structure A are smaller than structure B. The shear load at each layer is based on static equivalent force method using inverse triangle. $E=205 \mathrm{kN} / \mathrm{mm}^{2}, f_{y}=235 \mathrm{~N} / \mathrm{mm}^{2}$ for all the members. 


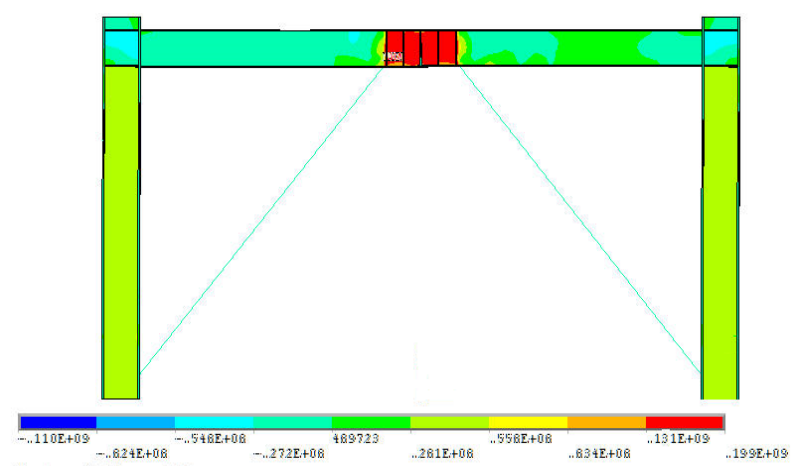

(a) Shear stress contour

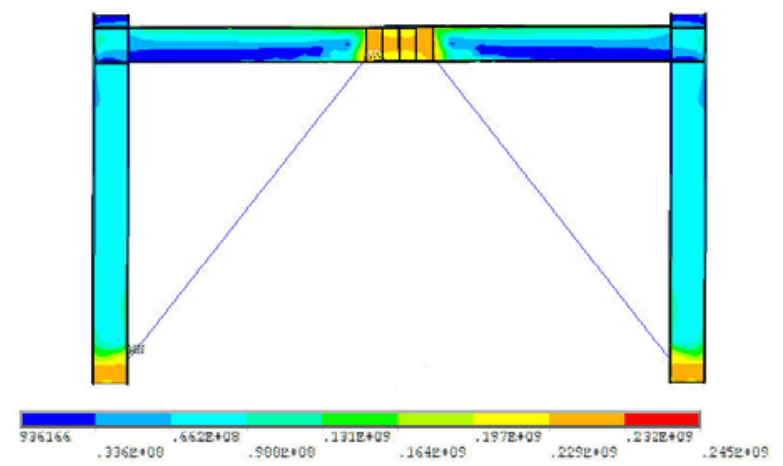

(b) Mises stress contour

Figure 12. Stress Contour of EBF with Shear Link

Shear yielding, strain hardening effect, geometric and material nonlinearity, shear deformation and residual stress are explicated in the advanced analyses of two EBFs. Two kinds of analyses are carried out: (1) NC-EBF: the effect of shear yielding and strain hardening is ignored in two EBFs; (2) C-EBF: the effect of shear yielding and strain hardening is considered in two EBFs. In the elastic stage, the loads and displacements of analyses (1) and (2) are the same because all the members are elastic. In the elastic-plastic stage, whether the effect of shear links is considered will influence the ultimate loads and displacements significantly. All the shear links in two EBFs are yielding from the analysis (2), and the yielding sequence is 2, 3 and 1, as shown in Figure 13. At last yielding occurs at column base, and all the other members are elastic. It is demonstrated that the two structures are designed rationally. The design requirements and expected goals of EBFs can be easily judged by using the proposed practical advanced analysis method. Numerical analysis also shows that the proposed method has a high efficiency as well as easy determination of the element yielding sequence. It can also make a conclusion that shear links should be yielded firstly and the other members are generally elastic for rational design of EBFs under severe earthquake. The load-displacement curves obtained by the analyses are shown in Figure 14.

Table 5. Summary of Selected Shapes and Sizes

\begin{tabular}{|c|c|c|c|c|c|c|}
\hline & \multicolumn{3}{|c|}{ Structure A } & \multicolumn{3}{|c|}{ Structure B } \\
\hline Storey & Braces & Columns & Beams & Braces & Columns & Beams \\
\hline 1 & HSS203x203x 8 & W310x79 & $\mathrm{W} 250 \times 45$ & HSS254x254x8 & W310x86 & W460x60 \\
\hline 2 & HSS178x178x8 & W310x79 & W200x31 & HSS203×203x9.5 & W310x86 & W360x39 \\
\hline 3 & HSS $152 \times 152 \times 8$ & W250x33 & W130x28 & HSS $152 \times 152 \times 9.5$ & W250x33 & W200x27 \\
\hline
\end{tabular}



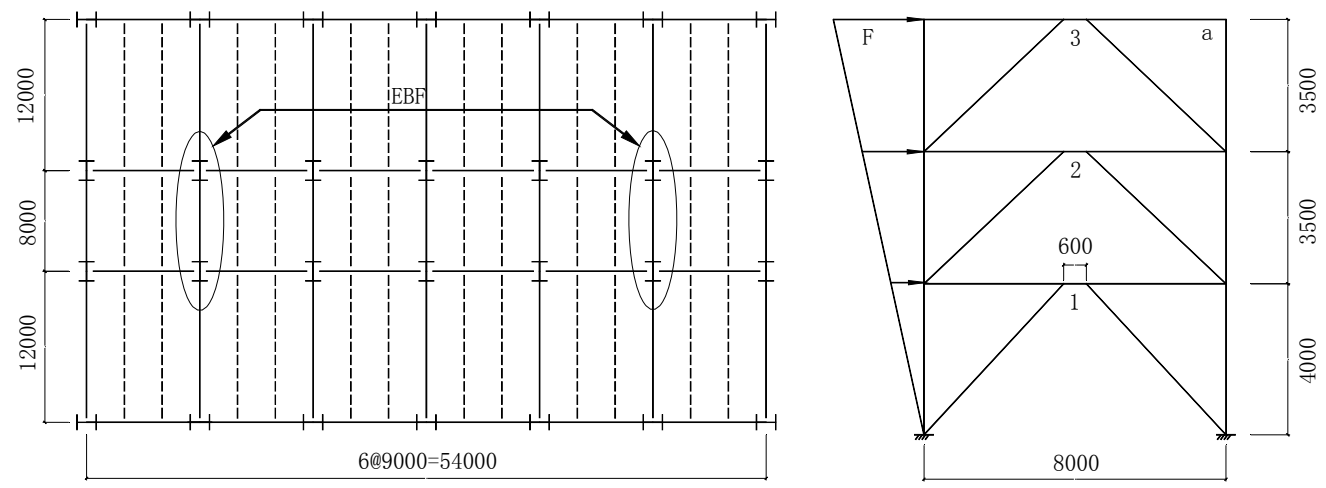

Figure 13. Layout and Elevation of Three-storey EBF

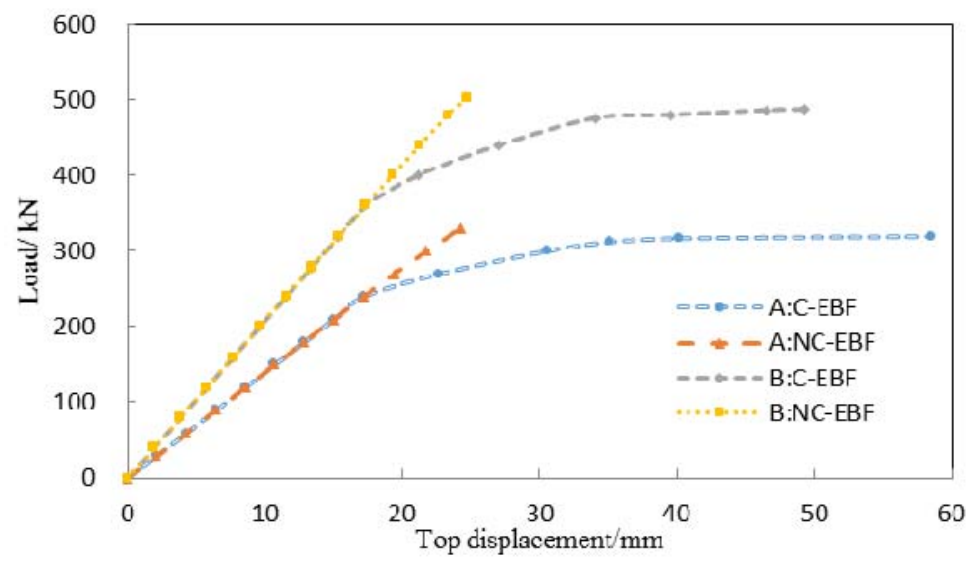

Figure 14. Load-displacement Curves of Two EBFs

\section{CONCLUSIONS}

A simple and effective model for practical advanced analysis of EBFs, which considers shear and flexural yielding behavior, geometric nonlinearity, material nonlinearity, shear deformation, residual stress, and strain hardening effect, is proposed in this paper. Based on the assumed multiple springs with zero-length at each end to simulate the yielding and the strain hardening effect, the element stiffness of shear and flexural links can be well predicted at different load level. The yield functions for links that derived by using the section assemblage method can be used to evaluate the loading bearing capacity of elements in elastic and inelastic range. Comparison analysis is conducted on the EBFs with flexural-yielding type and shear-yielding type links, and it shows that the strain hardening effect and stiffness variation effect are of crucial importance. Also, the proposed method has a high efficiency and accuracy by using one element or member only.

\section{ACKNOWLEDGEMENT}

The authors gratefully acknowledge the research grant provided by the National Nature Science Foundation of China (No. 51178192; 51378219; 51378009), State Key Laboratory of Subtropical Building Science Foundation, South China University of Technology (No. 2012ZA05). 


\section{REFERENCES}

[1] Kasai, K. and Popov, E.P., "General Behavior of WF Steel Shear Link Beams", Journal of Structural Engineering, ASCE, 1986, Vol.112, No.2, pp. 362-382.

[2] Kasai, K. and Popov, E.P., "Cyclic Web Buckling Control of Shear Link Beams", Journal of Structural Engineering, ASCE, 1986, Vol. 112, No. 3, pp. 505-523.

[3] Prpov, E.P. and Engelhardt, M.D., "Seismic Eccentrically Braced Frames", Journal of Constructional Steel Research, 1988, Vol. 10, pp. 321-354.

[4] Okazaki, T. and Engelhardt, M.D., "Cyclic Loading Behavior of EBF Links Constructed of ASTM A992 Steel”, Journal of Constructional Steel Research, 2007, Vol. 63, No. 6, pp. 751-765.

[5] Daneshmand, A. and Hosseini, B., "Performance of Intermediate and Long Links in Eccentrically Braced Frames". Journal of Constructional Steel Research, 2012, Vol. 70, pp. 167-176.

[6] Ricles, J.M. and Popov, E.P., "Inelastic Link Element for EBF Seismic Analysis", Journal of Structural Engineering, ASCE, 1994, Vol. 120, No. 2, pp. 441-463.

[7] Ramadan, T. and Ghobarah, A., "Analytical Model for Shear-link Behavior", Journal of Structural Engineering, ASCE, 1995, Vol. 121, No.11, pp. 1574-1580.

[8] Richards, P.W. and Uang, C.M., "Testing Protocol for Short Links in Eccentrically Braced Frames", Journal of Structural Engineering, ASCE, 2006, Vol. 132, No. 8, pp. 1183-1191.

[9] Liew, J.Y.R., White, D.W. and Chen, W. F., "Second-order Refined Plastic Hinge Analysis of Frame Design, Part 1", Journal of Structural Engineering, ASCE, 1993, Vol. 119, No. 11, pp. 3196-3216.

[10] Kim, S.E. and Chen, W.F., "Practical Advanced Analysis for Braced Steel Frames Design", Journal of Structural Engineering, ASCE, 1996, Vol.122, No.11, pp. 1266-1274.

[11] Chen, W.F., "Structural Stability: from Theory to Practice", Engineering Structures, 2000, Vol. 22, No. 2, pp. 116-122.

[12] Chan, S.L. and Chui, P.P.T., "A Generalized Design-based Elastoplastic Analysis of Steel Frames by Section Assemblage Concept”, Engineering Structures, 1997, Vol. 19, No. 8, pp. 628-636.

[13] Chen, W.F. and Lui, E.M., "Stability Design of Steel Frames", CRC Press, 1992.

[14] Chan, S.L. and Chui, P.P.T., "Non-linear Static and Cyclic Analysis of Semi-rigid Steel Frames", Elsevier Science, 2000.

[15] European Convention for Constructional Steelwork, "Ultimate Limit State Calculation of Sway Frames with Rigid Joints, ECCS", Technical Working Group 8.2, Systems, Publication No. 33, 1983.

[16] Ghobarah, A. and Ramadan, T., "Effect of Axial Forces on the Performance of Links in Eccentrically Braced Frames”, Engineering Structures, 1990, Vol. 12, No. 2, pp. 106-113.

[17] Shi, Y.J., Xiong, J. and Wang, Y.Q., "Experimental Studies on Seismic Performance of Multi-storey Steel Frame with Eccentric Brace”, Journal of Building Structures, 2010, Vol. 31, No. 2, pp. 29-34.

[18] Code for Seismic Design of Buildings, GB50010-2010, Beijing, China Architecture \& Building Press, 2010.

[19] Rozon, J., Koboevic, S. and Tremblay, R., "Study of Global Behavior of Eccentrically Braced Frames in Response to Seismic Loads", The $14^{\text {th }}$ World Conference on Earthquake Engineering, Beijing, 2008. 